\title{
Comparing Three Lane Merging Schemes for Short-Term Work Zones: A Simulation Study
}

\author{
Rami Harb, ${ }^{1}$ Essam Radwan, ${ }^{2}$ and Vinayak V. Dixit ${ }^{3}$ \\ ${ }^{1}$ CATSS, University of Central Florida, Orlando, FL 32816, USA \\ ${ }^{2}$ CATSS, Department of Civil and Environmental Engineering, University of Central Florida, Orlando, FL 32816, USA \\ ${ }^{3}$ Gulf Coast Research Center for Evacuation and Transportation Resiliency, Department of Civil and Environmental Engineering, \\ Louisiana State University, Baton Rouge, LA 70803, USA \\ Correspondence should be addressed to Rami Harb, ramyz5@yahoo.com
}

Received 23 August 2011; Accepted 27 September 2011

Academic Editors: J. D. Nelson and I. G. Raftoyiannis

Copyright ( 2012 Rami Harb et al. This is an open access article distributed under the Creative Commons Attribution License, which permits unrestricted use, distribution, and reproduction in any medium, provided the original work is properly cited.

Traffic safety and mobility of roadway work zones have been considered to be one of the major concerns in highway traffic safety and operations in Florida. Dynamic lane merging (DLM) systems_-ITS-based lane management technology—were introduced by several states in an attempt to enhance both safety and mobility of roadway work zones. Two forms of lane merging, namely, the early merge and the late merge were designed to advise drivers on definite merging locations. Up to date, there are no studies that contrast both merging schemes under matching work zone settings. This study simulates a two-to-one work zone lane closure configuration under three different Maintenance of Traffic (MOT) plans in VISSIM. The first MOT is the conventional plans used in Florida's work zones, the second MOT is a simplified dynamic early merging system (early SDLMS), and the third MOT is a simplified dynamic late merging systems (late SDLMSs). Field data were collected to calibrate and validate the simulation models. Simulation results indicated that overall, under different levels of drivers' compliance rate and different percentages of trucks in the traffic composition, the early SLDMS outperformed the conventional MOT and the late SDLMS in terms of travel times and throughputs.

\section{Introduction}

To improve traffic safety and mobility in work zone areas, several states of the USA explored the Dynamic Lane Merge (DLM) systems. The DLM systems are intelligent work zone traffic control systems that respond to real-time traffic changes via traffic sensors. The DLM systems are designed to advise drivers on definite merging locations and can take two forms: dynamic early merge and dynamic late merge. The idea behind the dynamic early merge is to create a dynamic no-passing zone to encourage drivers to merge into the open lane before reaching the end of a queue and to prohibit them from using the closed lane to pass vehicles in the queue and merge into the open lane ahead of them [1]. The concept behind late merge is to make more efficient use of roadway storage space by allowing drivers to use all available traffic lanes to the merge point. Once the merge point is reached, the drivers in each lane take turns proceeding through the work zone [2].

Several studies were undertaken to contrast the early form of the DLM $[1,3-5]$ or the late form of the DLM $[2,6-10]$ to existing Maintenance of Traffic (MOT) plans or standard MUTCD work zone traffic control plans. Whereas each study exposes the advantages and disadvantages of the tested systems, up to date there are no studies that cross compares both merging schemes (i.e., early and late DLM) under the same work zone settings.

Our research team at the University of Central Florida in accordance with the Florida DOT incorporated an ITS-based lane management system, namely, the DLM system, into the Florida conventional MOT plans known as the Motorist Awareness System (MAS) [11]. Two resulting modified MAS plans for two-to-one work zone lane closure configuration, identified as the Simplified Dynamic Lane Merging Systems 


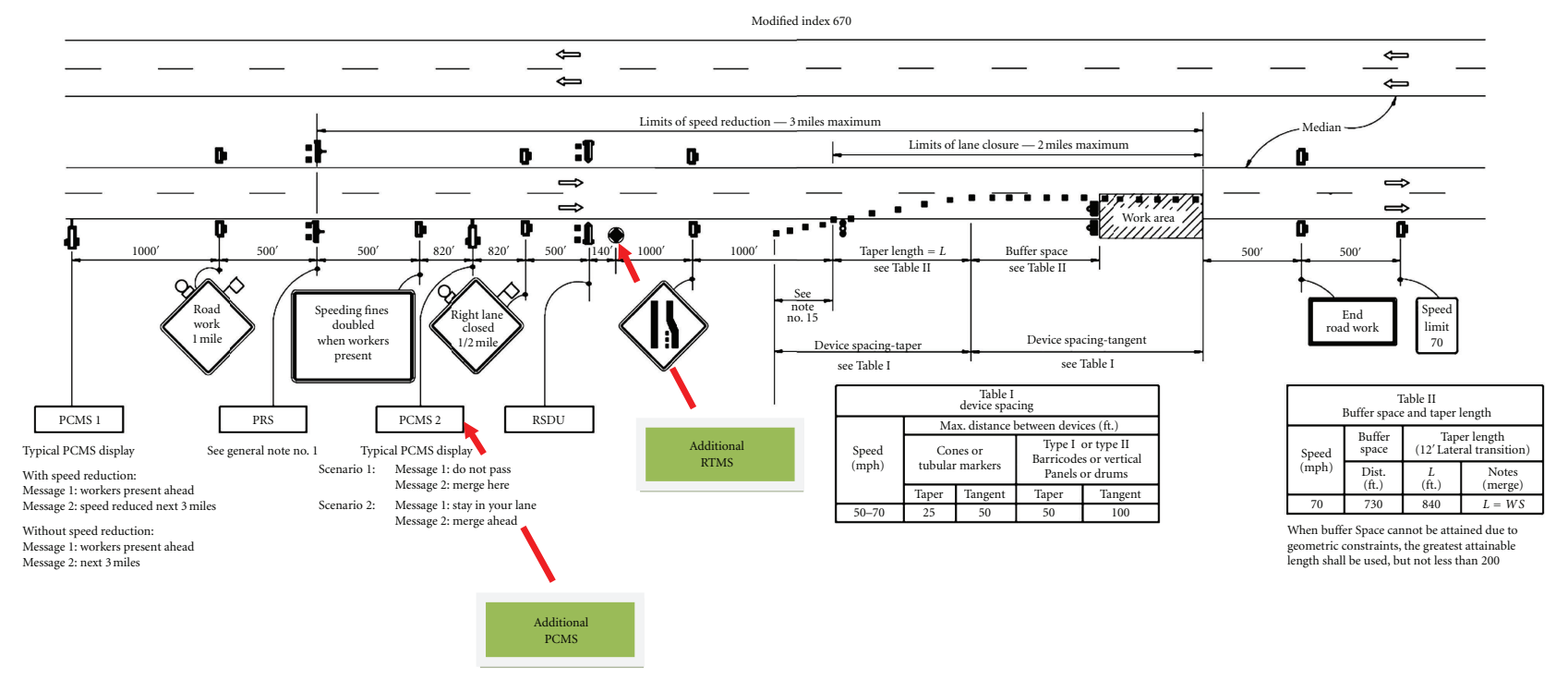

FIGURE 1: MAS plans and modifications.

(SDLMSs), were designed and deployed in the field. The first SDLMS is a simplified dynamic early merging system (early SDLMS) and the second system is a simplified dynamic late merging system (late SDLMS) [12]. Details about the DLM systems are provided in following sections. Field data collection was limited to two days under each MOT type; therefore recommendations were restricted to the observed field conditions. To expand on the findings hence to test the suggested systems under different vehicular and driver characteristics, microscopic simulation was used in this study.

There exist a wide range of tools to evaluate the safety and mobility of drivers at work zone lane closures. QUEWZ, QuickZone, and DELAY Enhanced 1.2 are analytical tools developed to assess traffic impacts at work zones. However, these tools in addition to the methodology presented by HCM 2000 do not offer the flexibility of adjusting for the lane management strategy (DLM) suggested in this study. VISSIM is microscopic stochastic simulation package that enables the creation of specific scenarios (e.g., DLM logic) via vehicle-actuated programming (VAP). A program reflecting our algorithm (DLM logic) was coded to communicate with VISSIM in real time. The next sections introduce VISSIM and elaborate on the methodology followed in simulating the dynamic lane merging in VISSIM.

The objective of this research is to compare amongst the early and late SDLMSs and the conventional MAS used in Florida to identify the operational effectiveness of each MOT plan and to make recommendations on the implementation of the suggested systems. The scope of the objective is restricted to freeway work zones consisting of a two-to-one lane closure configuration. The effectiveness of each MOT type is determined for different levels of drivers' adherence to the messages displayed by the systems, different levels of truck percentages in the traffic composition, and different levels of demand volumes.

The remainder of this paper is organized as follows: MAS, early and late SDLMS description, VISSIM simulation including network coding and VAP coding to mimic the SDLMS logic, field data collection, calibration, and validation of the simulation models. Finally, scenario runs with different levels of drivers' compliance, truck percentages, and demand volumes are presented, followed by conclusions and recommendations.

\section{Motorist Awareness System (MAS) and Early/Late SDLMS}

Currently the Florida Department of Transportation deploys an MOT plan known as the Motorist Awareness System (MAS). According to the Florida Plans Preparation Manual (PPM), the MAS consists of Portable Regulatory Signs (PRSs) highlighting the regulatory speed for the work zone and a Radar Speed Display Unit (RSDU) displaying the motorist's work zone speed. The MAS also comprises a Portable Changeable Message Sign (PCMS), a lane drop warning sign, and a sspeeding fines doubled warning sign, in addition to road work ahead warning signs [11]. The early and late SDLMSs consist of supplementing the conventional MAS plans with one Portable Changeable Message Sign (PCMS) and a nonintrusive sensor (Remote Traffic Microwave Sensor, RTMS) trailer as shown in Figure 1. The messages displayed by the PCMS define whether the system is an early or late SDLMS system. It should be noted here that the locations of the additional PCMS and the sensor trailer are identical for the early and late SDLMS.

The SDLMS operates under two modes: the passive mode and the active mode. Under the passive mode, the additional 


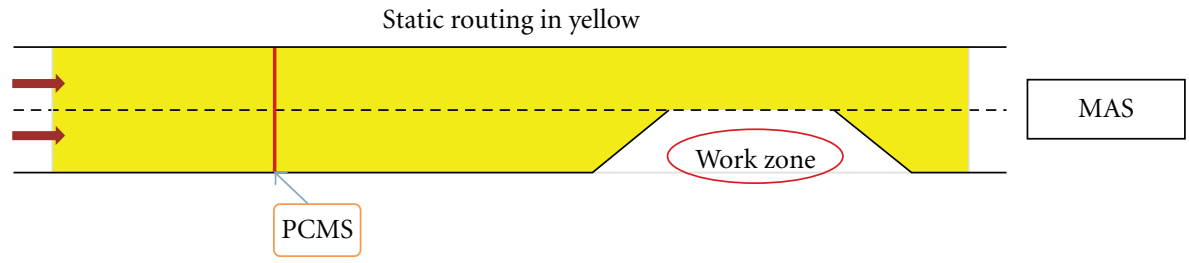

(a)

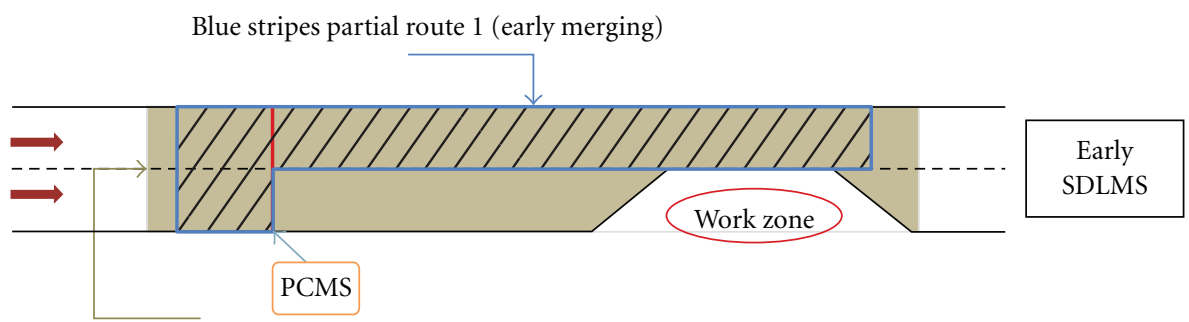

Brown solid partial route 2 (regular merging, PCMS not activated)

(b)

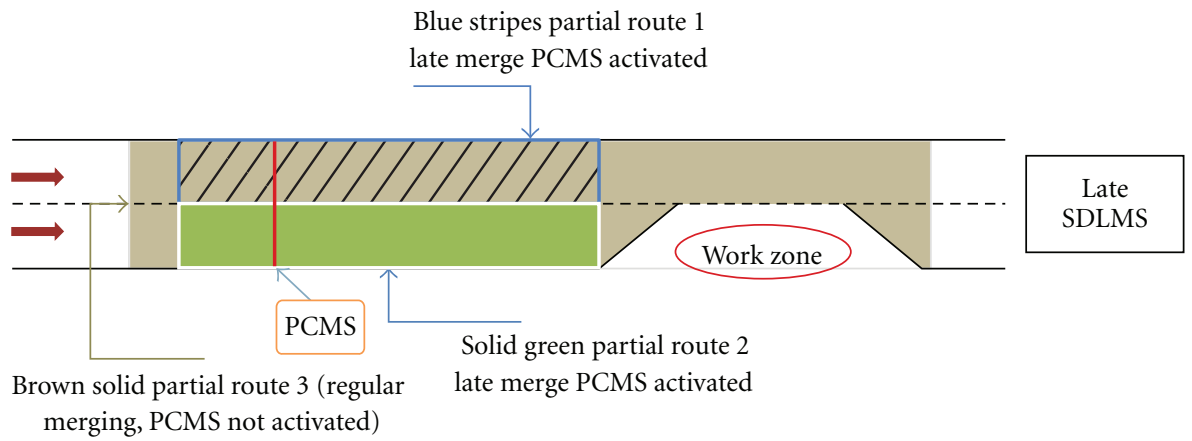

(c)

Figure 2: Partial and static decision routings.

PCMS is set to display a flashing "CAUTION/CAUTION" message for both the early and late SDLMS. Under the active mode, the PCMS displays "DO NOT PASS" followed by "MERGE HERE" alternately for the early SDLMS and "STAY IN YOUR LANE" followed by "MERGE AHEAD" alternately for the late SDLMS. The early and late SDLMS are activated once the average speed over any 2-minute time interval drops below $50 \mathrm{mph}$. The SDLMS will be deactivated (passive mode) once the average speed over the next time stamp goes over $50 \mathrm{mph}$. It should also be noted that the minimum activation time of the PCMS was set for 5 minutes.

\section{VISSIM Simulation}

VISSIM is a microscopic, time step, and behavior-based simulation model. VISSIM is a commercially available traffic simulation package developed by PTV AG, Karlsruhe, Germany, and distributed in the United States by PTV America, Inc. [13]. To build roadways in VISSIM, a series of links and connectors were used to represent the actual geometry of the work zone. It should be noted that the MOT plan used in the field was first scaled to match the dimensions embedded into the VISSIM elements. The roadway was traced on top of the image with links and connectors. The first node represents the first work zone PCMS. The second node represents the location of the additional PCMS where merging information is provided to drivers. Node 3 represents the lane closure start (1 lane open). Node 4 represents the lane closure end (two lanes open).

The next step was to mimic the SDLMS logic in VISSIM. Recalling the SDLMS algorithm applied in the field, first the RTMS captures the average speed of vehicles over twominute time intervals and the built-in algorithm checks if the speed threshold is reached. If the speed threshold is reached, the additional PCMS displays the necessary messages. The PCMS keeps displaying the messages until another speed threshold is reached. When the early SDLMS message is displayed, drivers merge to the open lane. When the late SDLMS message is displayed, drivers stay in their lane until the taper. To mimic the early SDLMS in VISSIM, partial decision routing was designated. Drivers either follow a decision routing designated to merge early (when speed drops below threshold) or follow a random merging (when speed remains above speed threshold). For instance, in Figure 2, the striped region is designated as partial route 1 (PCMS activated, early merge instructions) and the solid color region is designated 
as partial route 2 (PCMS not activated, random merging). The alternation between partial route 1 (early merge/PCMS activated) and partial route 2 (PCMS not activated, random merging) was controlled by the VAP. Two loop detectors were placed (in VISSIM) at the same location of the RTMS. The loop detectors in VISSIM capture individual vehicles speed. These loop detectors can communicate with signal controllers and can only interact with traffic signals. Since loop detectors cannot directly communicate with the routing decision, Vehicle-Actuated Programming (VAP) is used. VAP "is an optional add-on to VISSIM for the simulation of programmable, phase or stage based, traffic actuated signal controls. The control logic is coded in a txt file format and the VAP interpret the control logic commands and creates commands for the VISSIM network. At the same time various detectors variables reflecting the current traffic situation are retrieved from the simulation and processed in the logic" [13]. The same logic was followed for coding the late SDLMS in VISSIM. However, three partial routes were created. Partial routes 2 and 3 for late merge and partial route 1 for random merging. As for the MAS there was no need for partial routes, only one static routing decision was created.

An important factor in the SDLMS is the driver's compliance rate to the messages displayed by the PCMS. To reflect compliance rate in the simulation model, and since partial routing decision can control specific vehicle classes, four vehicle classes are created; Obey_car, Obey_TRK, and Disobey_car, Disobey TRK. Obey_car and Obey_TRK vehicle classes represent the vehicles that are controlled by the partial routing decision therefore complying with the PCMS messages. The Disobey_car and Disobey_TRK are not controlled by partial routing decision constituting the noncomplying vehicles. The traffic composition was set to contain all 4 vehicle classes. The traffic composition was modified manually to reflect different levels of compliance.

\section{Field Data Collection}

The selected site was located on Interstate-95 in Malabar, Florida. I-95 is 2-lane per direction limited access rural freeway with $70 \mathrm{mph}$ speed limit (reduced to $60 \mathrm{mph}$ during work). The work zone consisted of a resurfacing and milling job on the south bound of I-95 on a 13-mile stretch. A 2 to 1 lane closure configuration was adopted and the work zone moved on a daily basis covering a length of approximately 3 miles per day. Data was collected on homogenous basic freeway segment of I-95 with no on/off ramps.

Four digital camcorders were set in the field in addition to the RTMS. Demand volume, vehicle classification, throughput volumes, and travel times through the work zone were recorded and extracted in the laboratory. Under the standard MAS configuration, data was collected on February 11th and 12th, 2008, under the early SDLMS data was collected on March 17th and 18th, 2008, and under the late SDLMS data was collected on March 27th and 28th, 2008.

\section{Calibration and Validation of the VISSIM Model}

The calibration process in VISSIM was divided into several steps. First, travel time through the work zone was selected as the index of comparison. Second, the required number of simulation runs was determined. Third, an initial evaluation was conducted with the VISSIM's driving behavior's default parameters. If the selected measure of effectiveness is different in simulated and real conditions, the following step would be necessary. Fourth, an examination of the key parameters was conducted and calibration parameters were determined. Multiple runs with different values of the key parameters were run by trial and error until the calibration is completed. Fifth, for the model validation, the work zone throughput (different dataset) was used to verify the homogeneity between the real and simulated environment.

5.1. Number of Required Simulation Replications. VISSIM is stochastic simulation model; therefore one should determine the required simulation repetitions to prove statistical significance. The random individual vehicle properties are assigned based on the random seed number used for each simulation run. Due to each run's variance, multiple repetitions of the same model with different seed numbers were required to estimate the mean value with a certain level of confidence that the true mean falls within a target interval [14]. Since prior simulation variation data was not available, preliminary simulations were run and the following equation was used to determine the minimum required number of runs:

$$
\mathrm{CI}_{(1-\alpha) \%}=2 \times t_{(1-\alpha), N-1} \frac{s}{\sqrt{N}}
$$

where $\mathrm{CI}_{(1-\alpha) \%}$ equals $(1-\alpha) \%$ confidence interval for the true mean, where alpha equals the probability of the true mean not lying within the confidence interval. $t_{(1-\alpha / 2), N-1}$ that equals Student's $t$-statistic for the probability of a twosided error summing to alpha with $N-1$ degrees of freedom, where $N$ equals the number of repetitions. $S$ is the Standard deviation of the model results.

It was determined that a minimum of 3 replications (C.I. $N=3<15.33$ ) is required with the $95 \%$ confidence interval. It was decided that 10 replications (called replications later on) are to be conducted.

5.2. Initial Network Evaluation. In this step of the calibration process, the simulation model is run with VISSIM's driving behavior default values including the car following driver behavior set and the lane changing driver behavior parameter set. In order to determine whether the default driving behavior parameter set provides acceptable travel time values, ten replications with different seed numbers were executed. Average travel time through the work zone was recorded in VISSIM and compared to the field-observed travel time. Table 1 shows that the mean relative percent error is about $4.04 \%$ which is lower than the $5 \%$ conventional threshold. A $t$-test was conducted to compare those means and the resulting $P$ value $(0.350)$ demonstrated no significant 


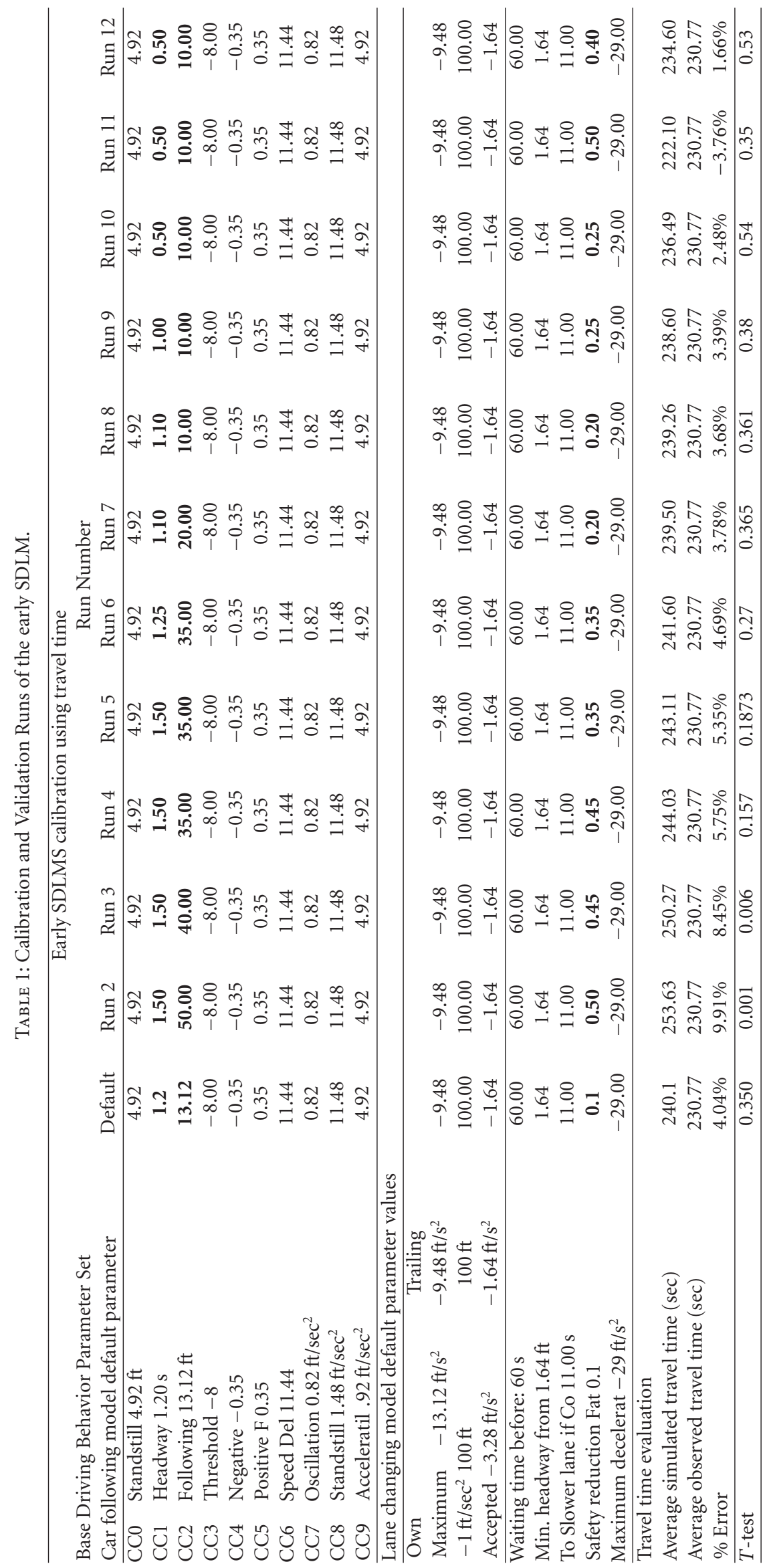




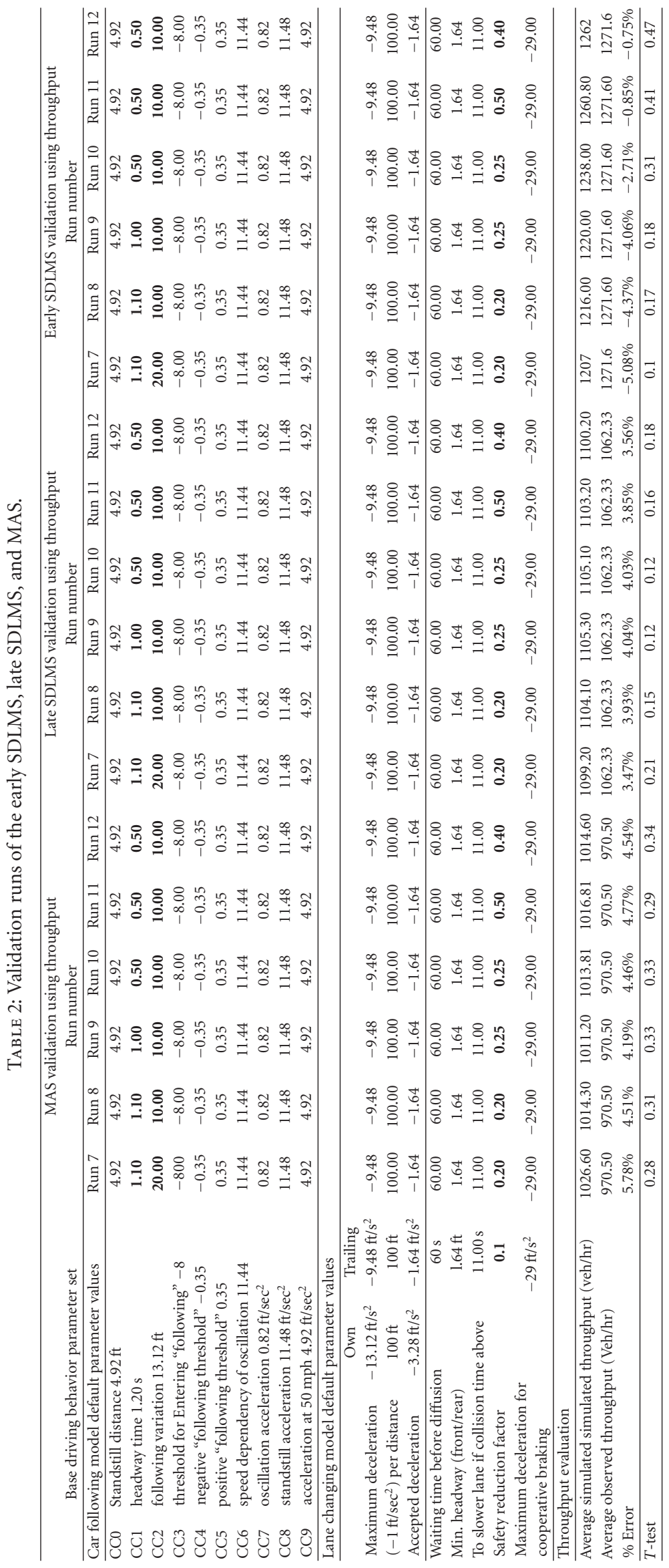




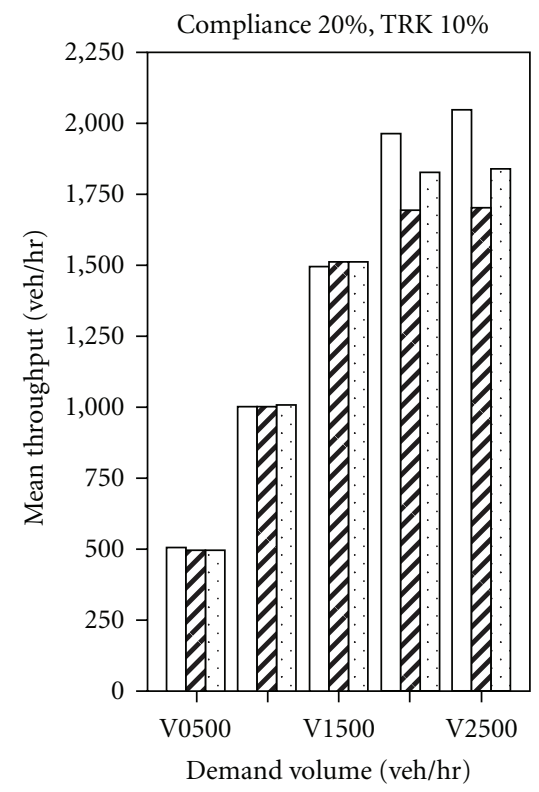

MOT type

$\square$ Early

$\square$ Late D

$\square$ MAS

(a)

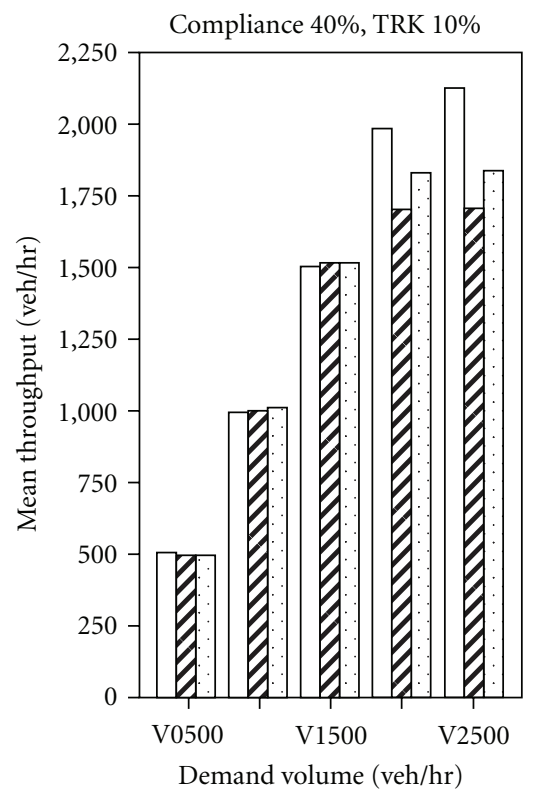

MOT type

$\square$ Early

$\square$ Late

$\square$ MAS

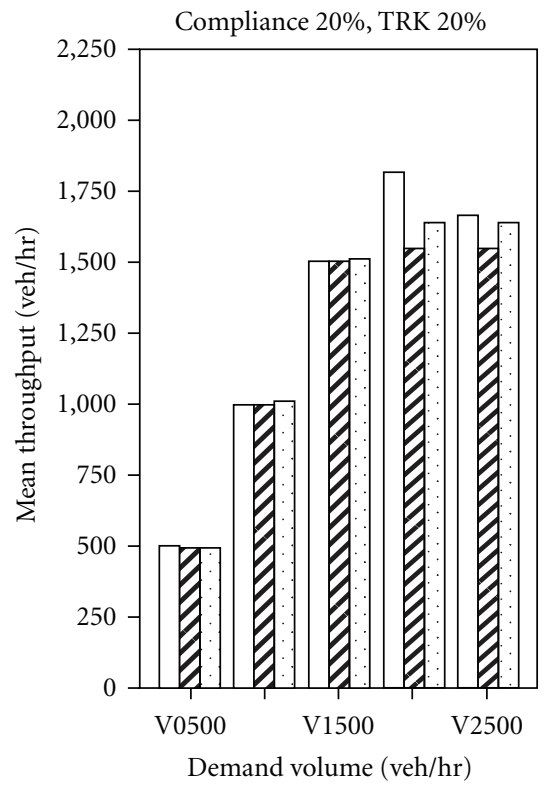

MOT type

$\square$ Early

$\square$ Late

$\square$ MAS

(b)

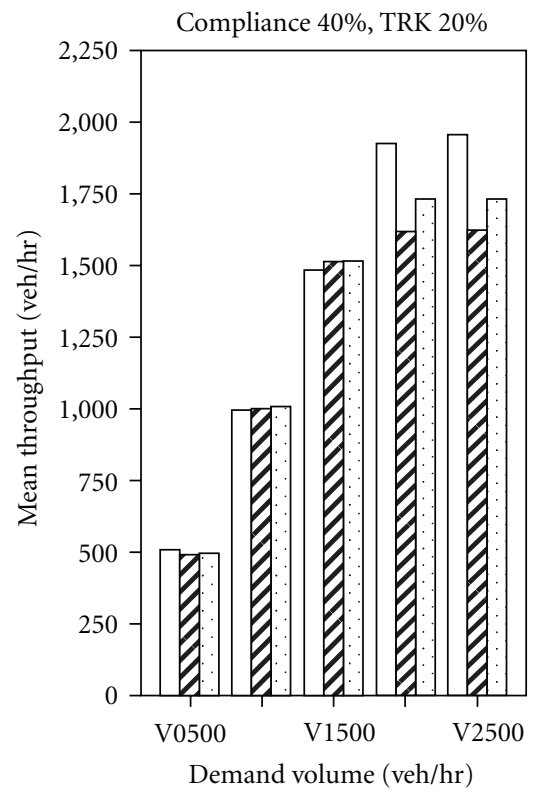

MOT type

$\square$ Early

$\square$ Late

$\square$ MAS

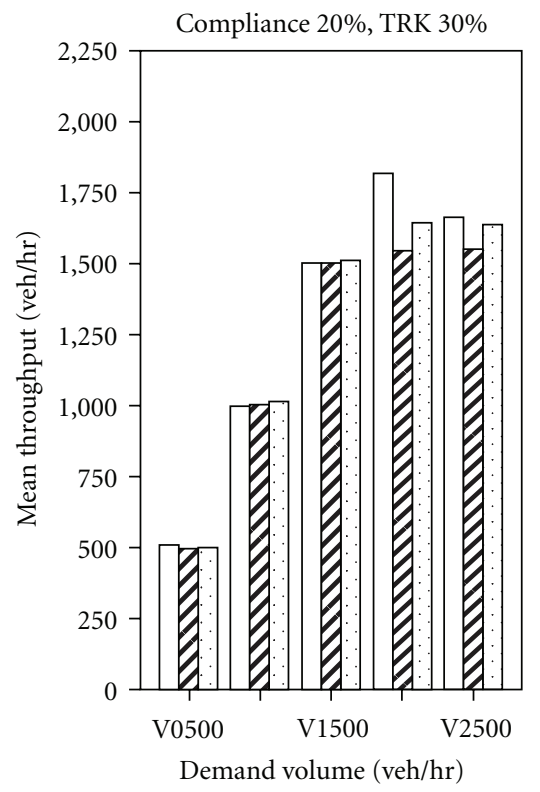

MOT type

$\square$ Early

\ Late

$\square$ MAS

(c)

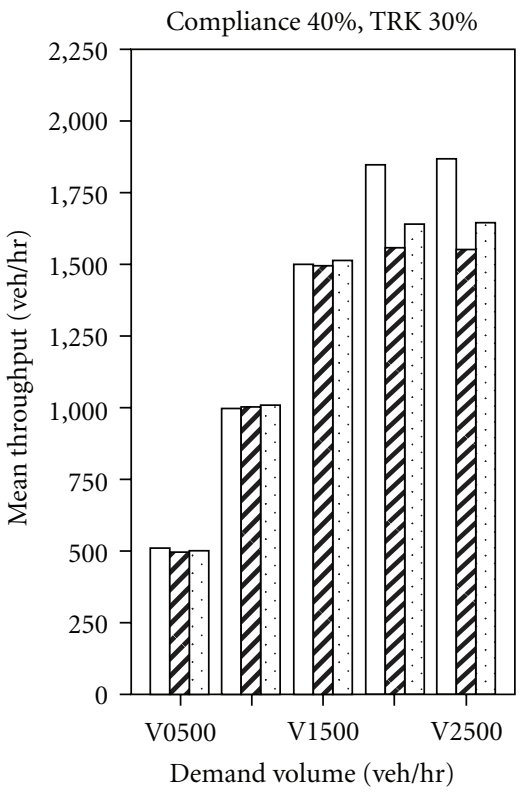

MOT type

$\square$ Early

$\square$ Late

$\square$ MAS

(d)

(e)

Figure 3: Throughputs under different combinations (C20, C40). 


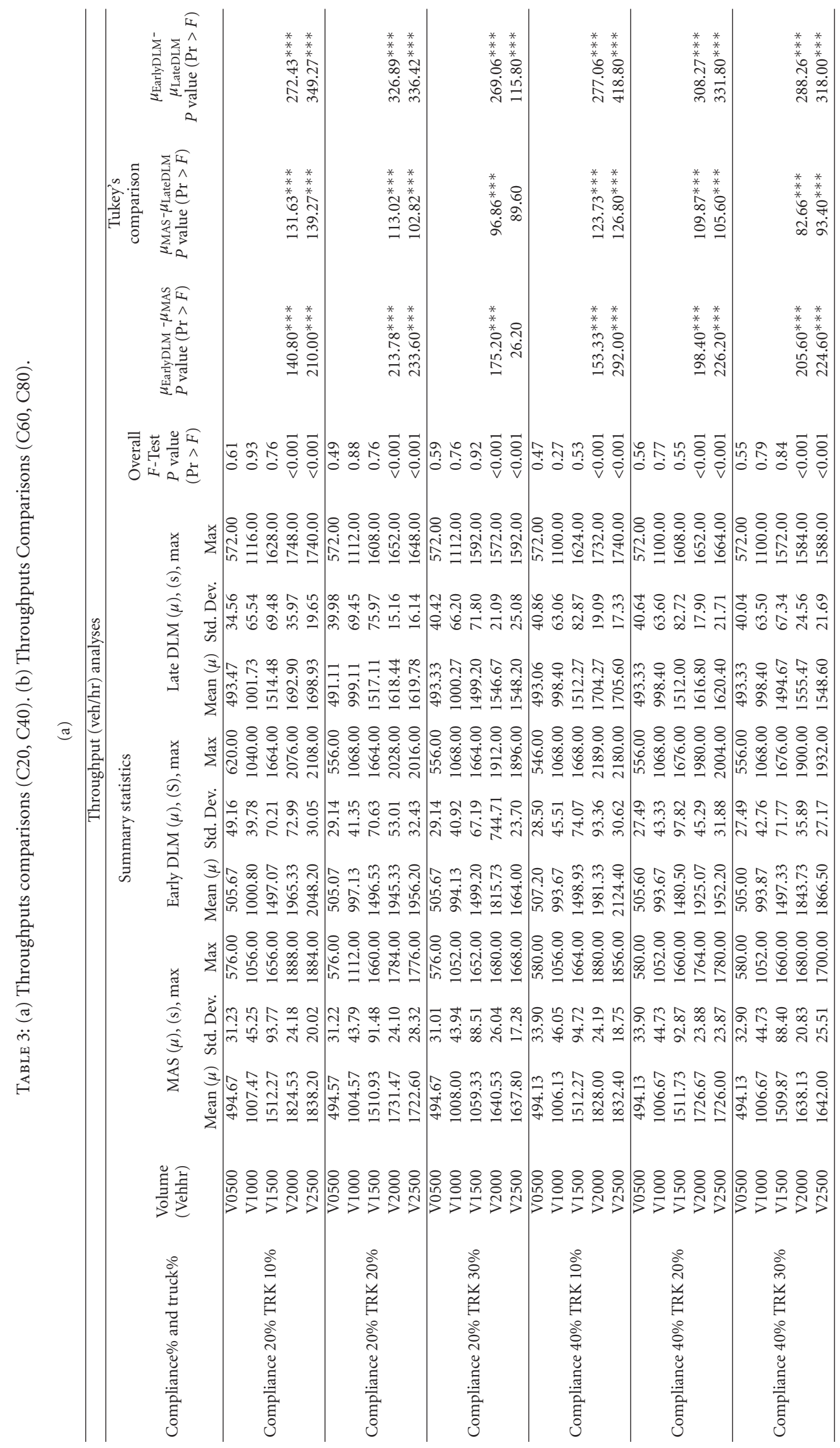




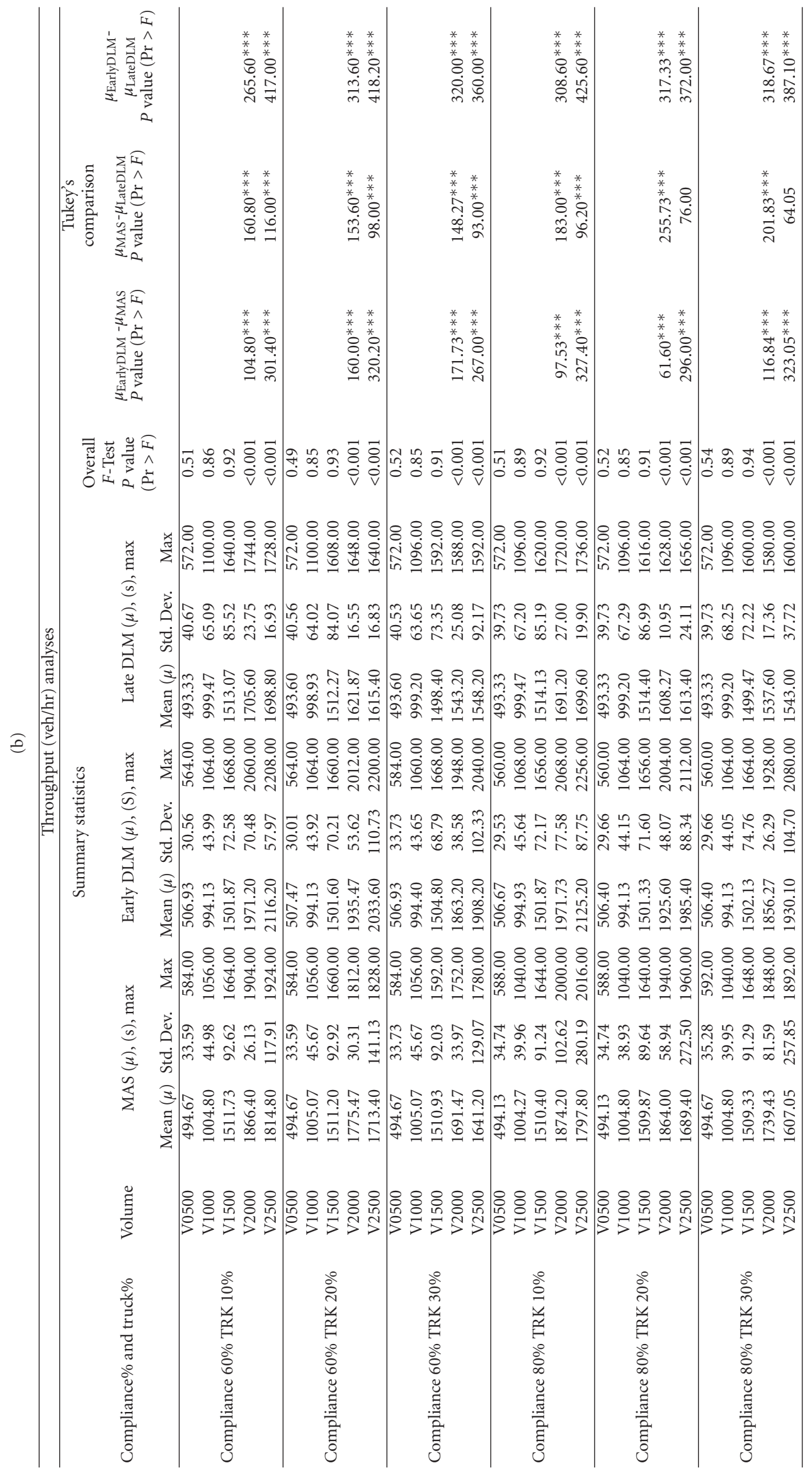




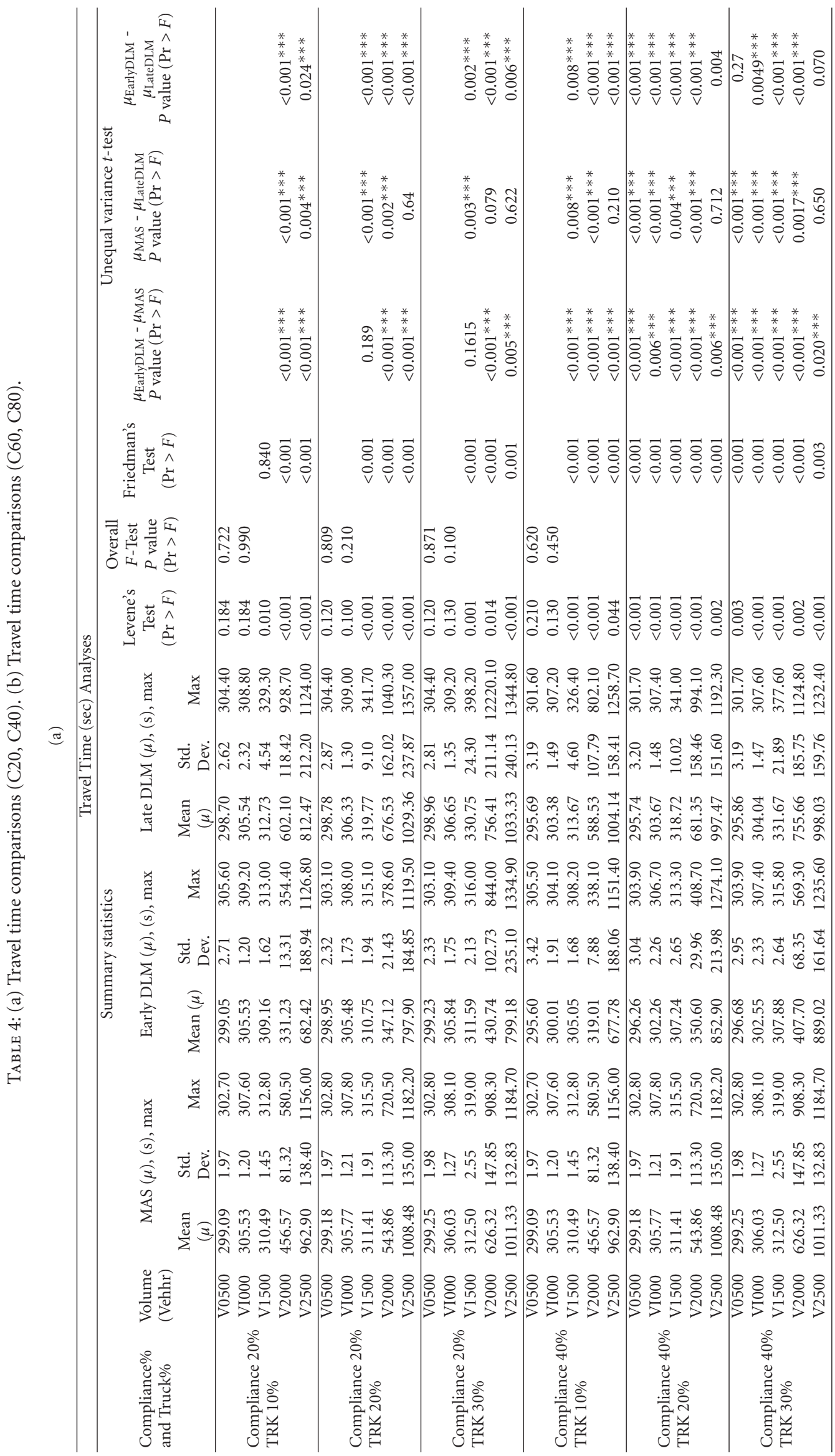




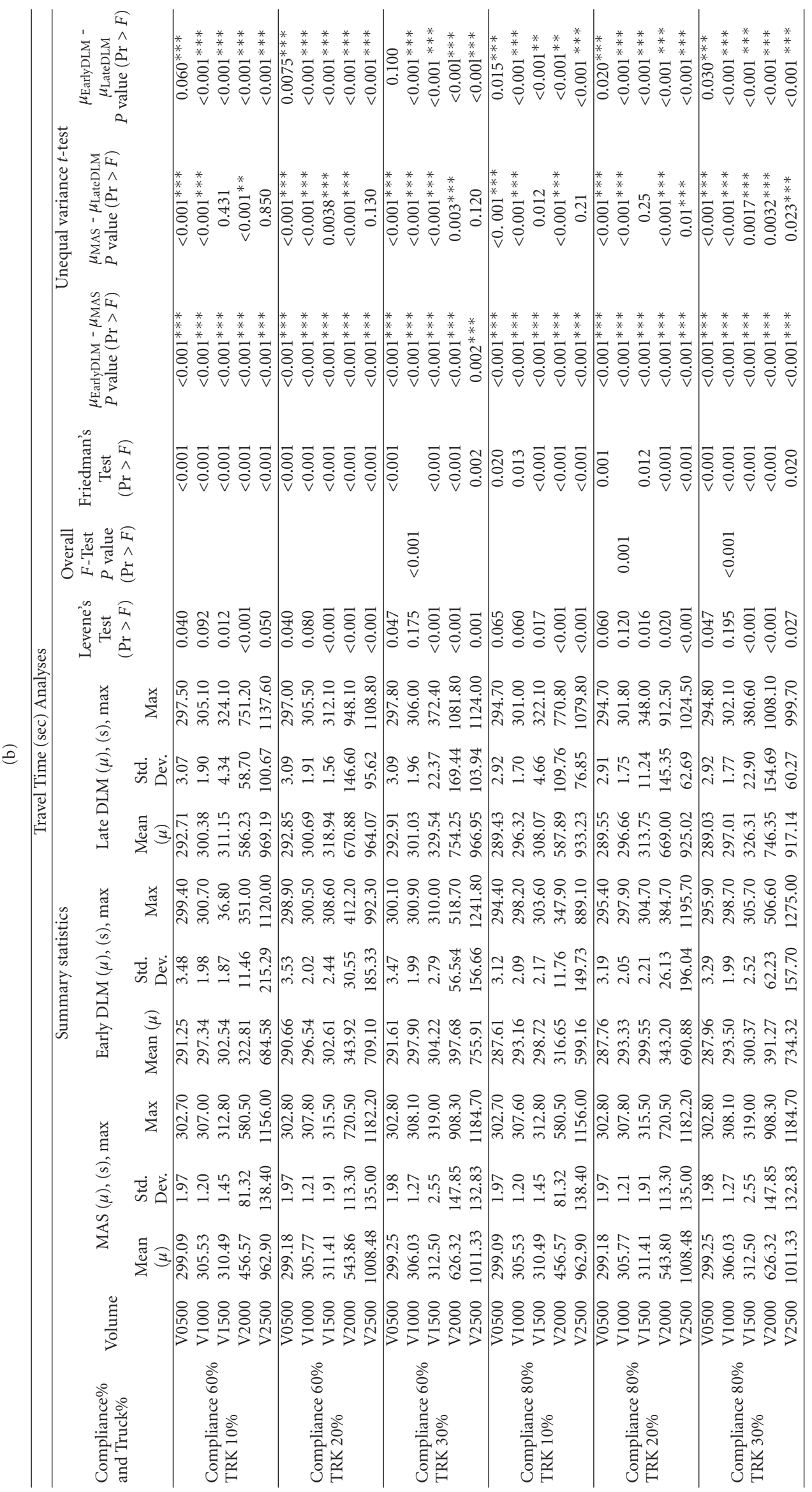




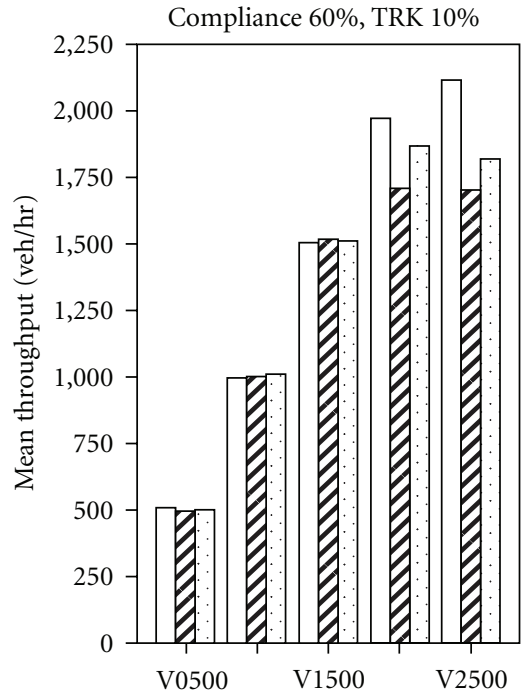

Demand volume (veh/hr)

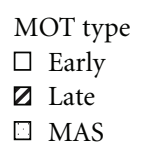

(a)

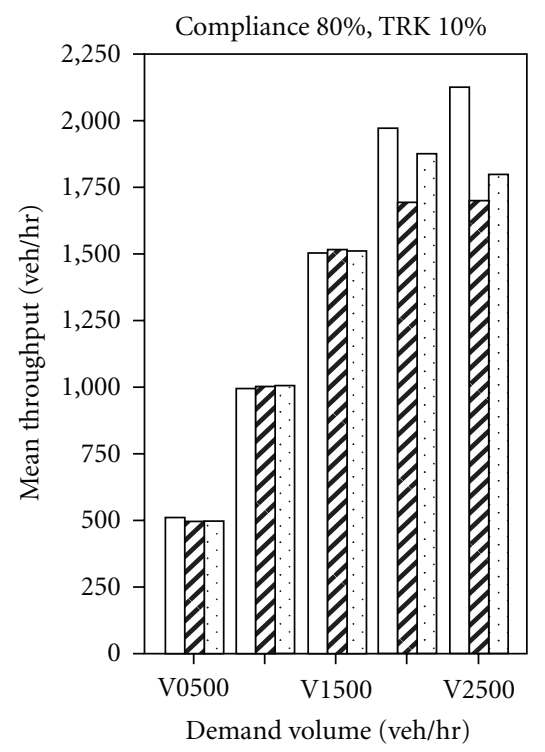

MOT type

$\square$ Early

$\square$ Late

$\square$ MAS

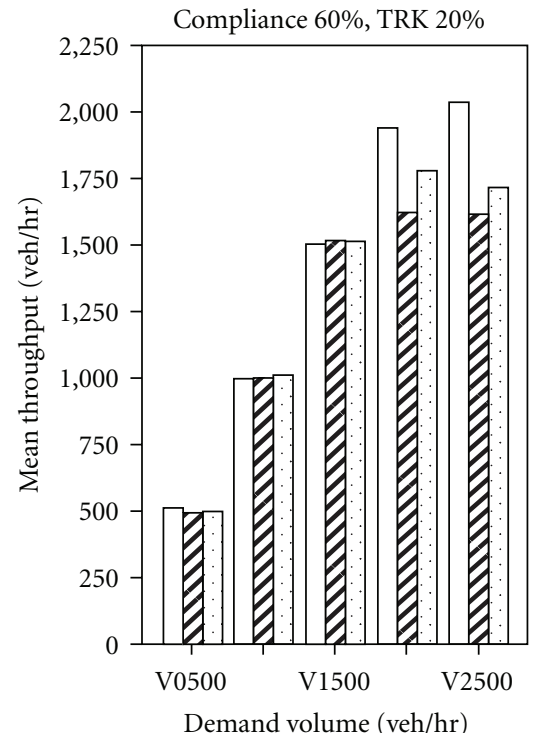

MOT type

$\square$ Early

$\checkmark$ Late

$\square$ MAS

(b)

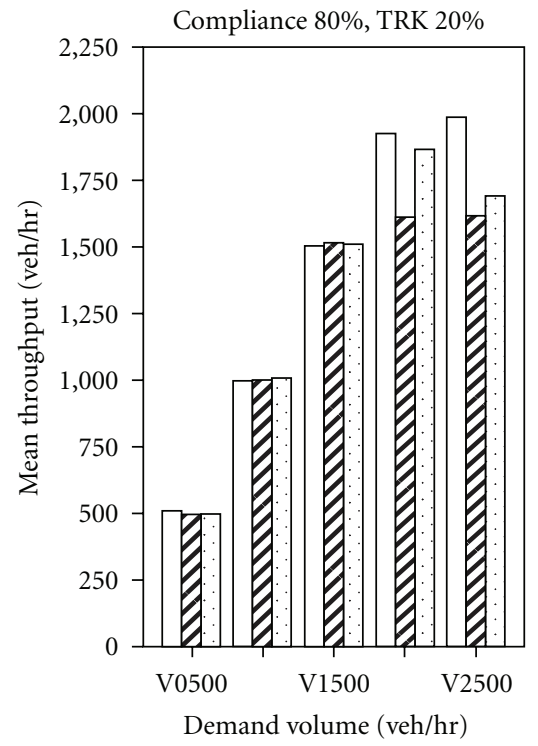

MOT type

$\square$ Early

Z Late

$\square$ MAS

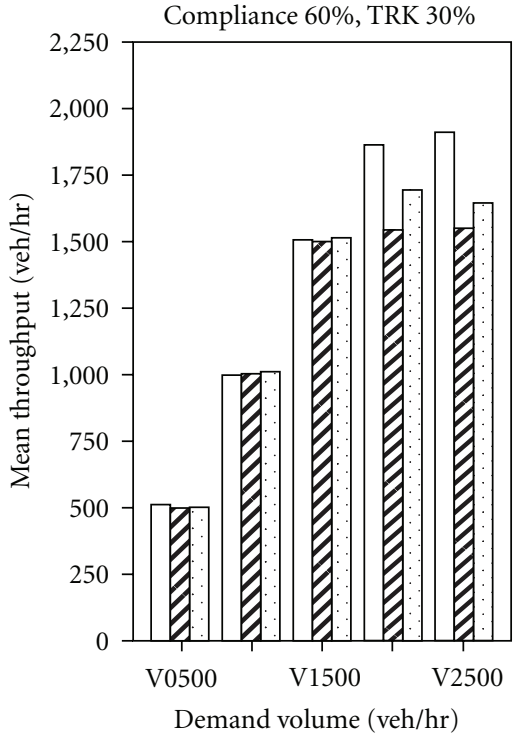

MOT type

$\square$ Early

Z Late

$\square$ MAS

(c)

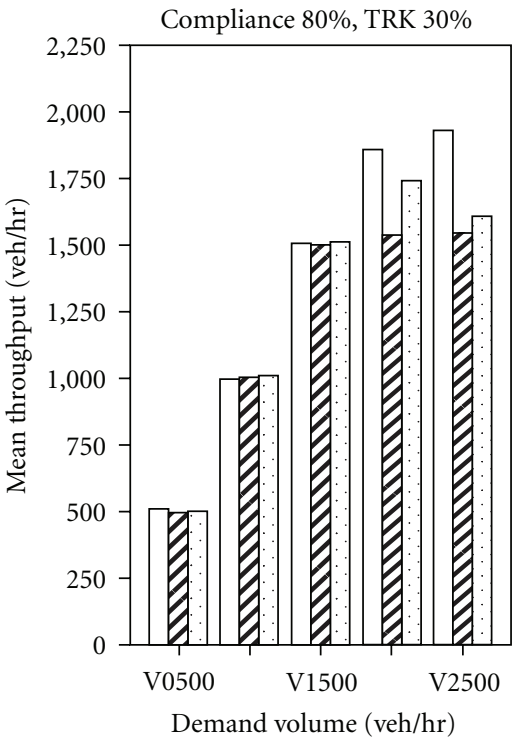

MOT type
$\square$ Early
$\square$ Late
$\square$ MAS

(f)

(d)

(e)

FIgURE 4: Throughputs under different combinations (C60, C80).

difference between the simulated and field observed travel times. Although the initial evaluation run shows no need for calibration, a calibration process was conducted to reduce the errors.

5.3. Driver Behavior Parameter Selection and Calibration. Before tackling the calibration process, a literature review was conducted to evaluate previous freeway and work zone simulation calibration and validation methods. Previous literature showed that in VISSIM the parameters CC0, CC1, CC2, CC4/CC5, and SRF are suited for model calibration of a work zone. Chatterjee et al. [15] argued that between the two parameters $\mathrm{CC} 0$ and $\mathrm{CC} 1$ that determine the safety distance $d_{x \text { safe }}=\mathrm{CC} 0+\mathrm{CC} 1 * v$ (that in turn determines 


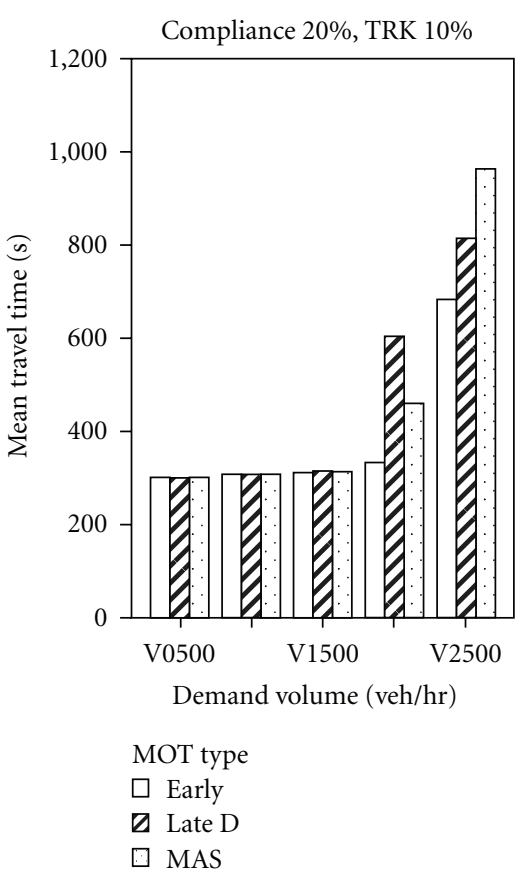

(a)

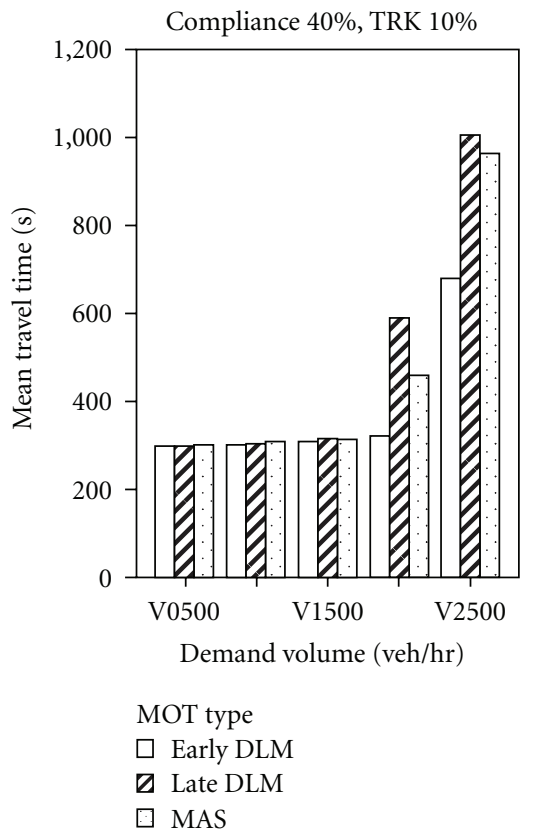

(d)

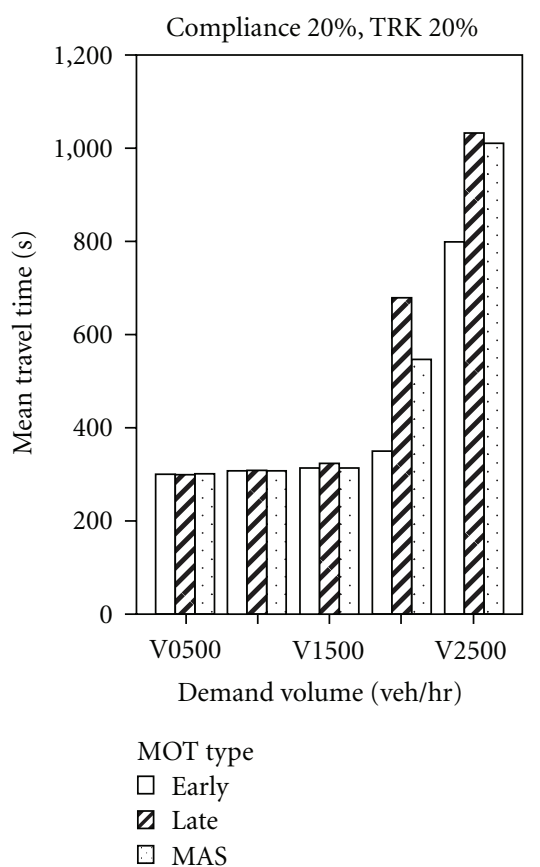

(b)

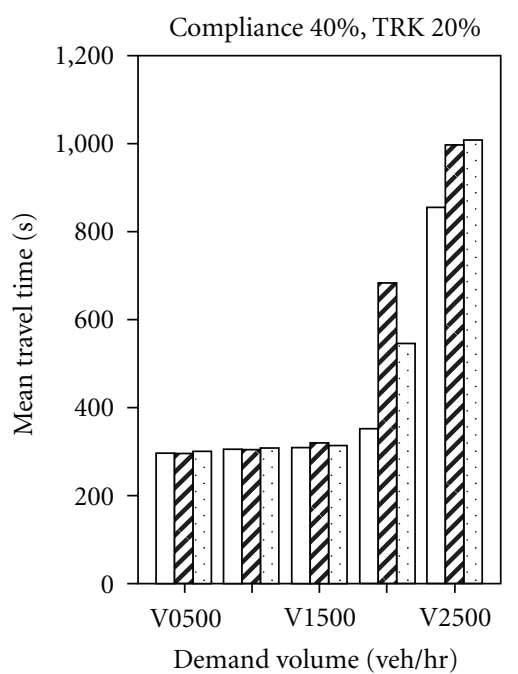

MOT type

$\square$ Early DLM

$\square$ Late DLM

$\square$ MAS

(e)

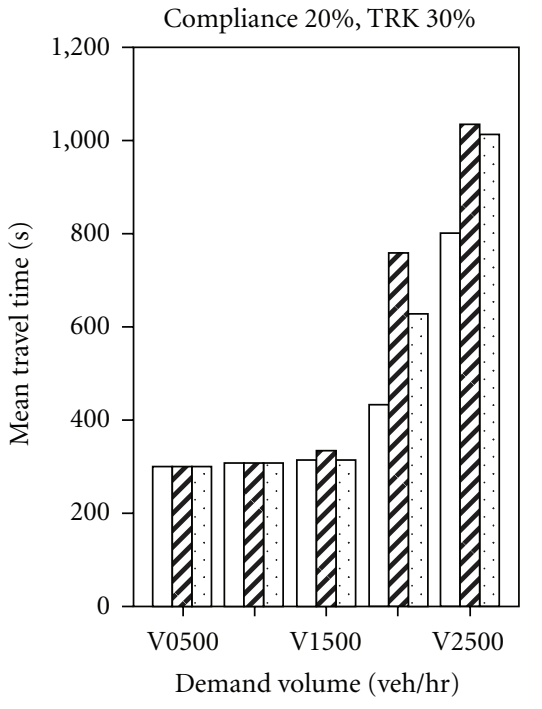

$$
\begin{aligned}
& \text { MOT type } \\
& \square \text { Early } \\
& \square \text { Late }
\end{aligned}
$$$$
\square \text { MAS }
$$

(c)

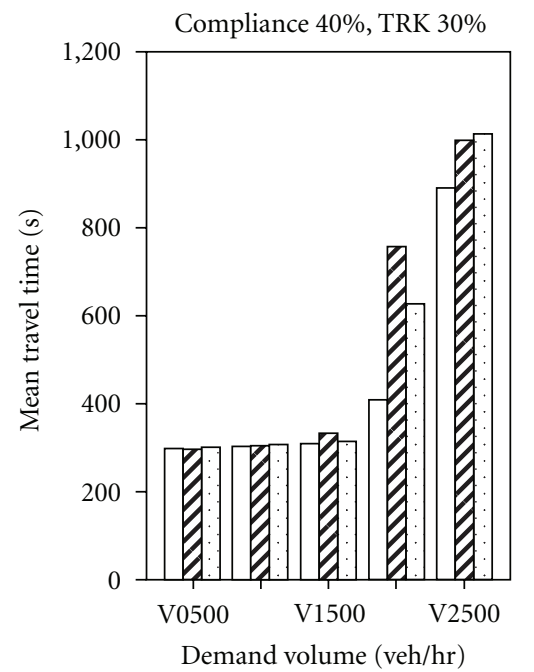

MOT type
$\square$ Early DLM
$\square$ Late DLM
$\square$ MAS

(f)

Figure 5: Travel time under different combinations (C20, C40).

capacity) only CC1 has a significant effect on the safety distance. According to the same study, it was concluded from visual interpretation that CC4/CC5 pair less than 3 resulted in unstable car following process and values higher than 3.0 did not result in variation of the MOE. After examining previous driving behavior calibration parameter selection, it was decided that $\mathrm{CC} 0$ and $\mathrm{C} 4 / \mathrm{C} 5$ pair be dropped. The selected parameters for this calibration process are CC1, CC2, and Safety Reduction Factor (SRF): CC1 ranging between $0.9 \mathrm{~s}$ and $1.8 \mathrm{~s}, \mathrm{CC} 2$ ranging between $10 \mathrm{ft}$ and $55 \mathrm{ft}$, and SRF ranging between 0.1 and 0.55 .

The calibration process was conducted by trial and error and evaluated using travel time through the work zone. Different combinations of these parameters were created. CC1 was incremented by 0.1 seconds, CC2 by $5 \mathrm{ft}$, and SRF by 0.05 . CC1, CC2, and SRF resulted in 10 intervals each. Therefore $10^{3}=1,000$ combinations of these parameters are possible. To minimize the 1,000 possible combinations, a 

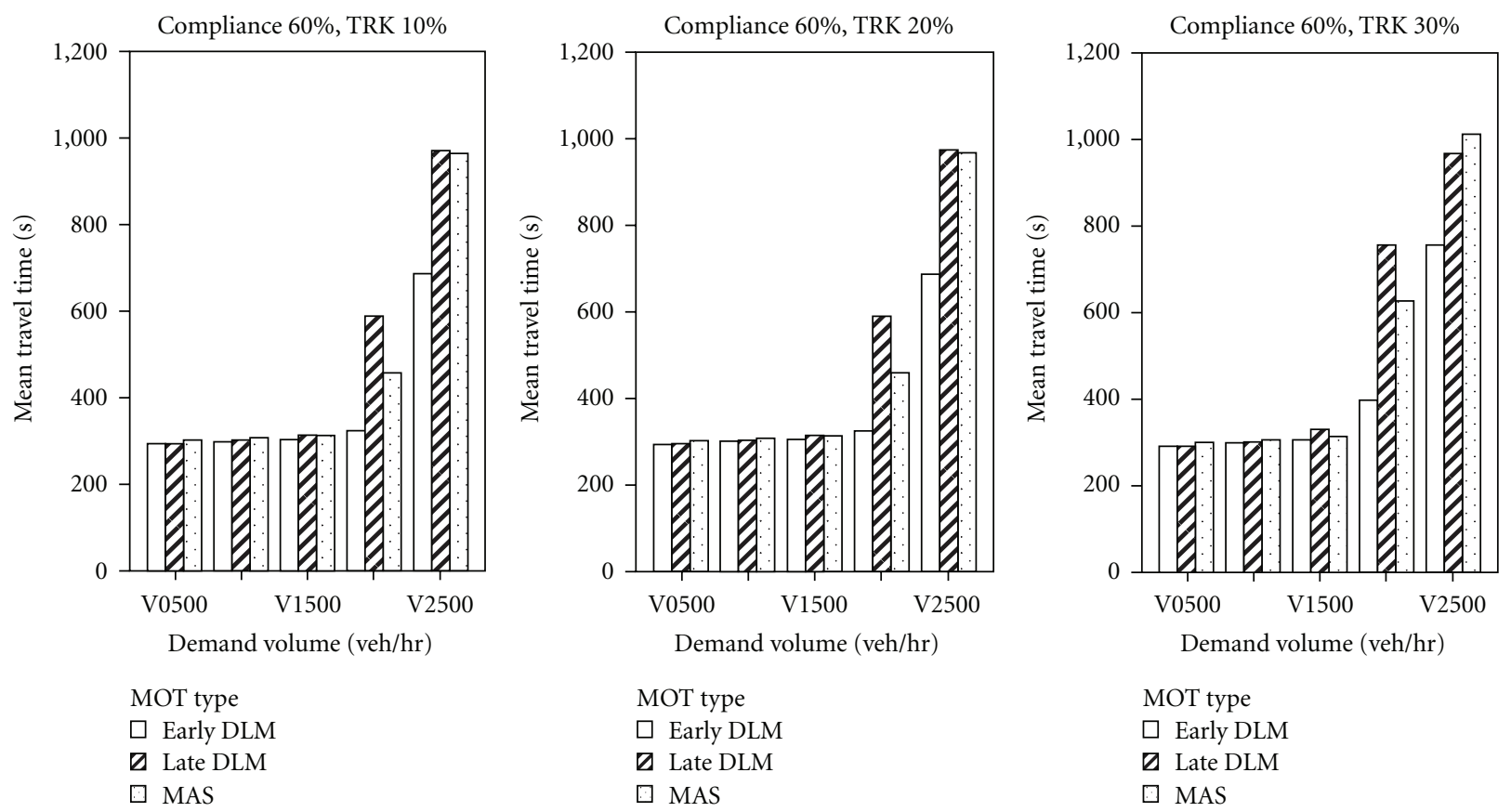

\section{MOT type \\ $\square$ Early DLM \\ $\square$ Late DLM \\ $\square$ MAS}

(a)

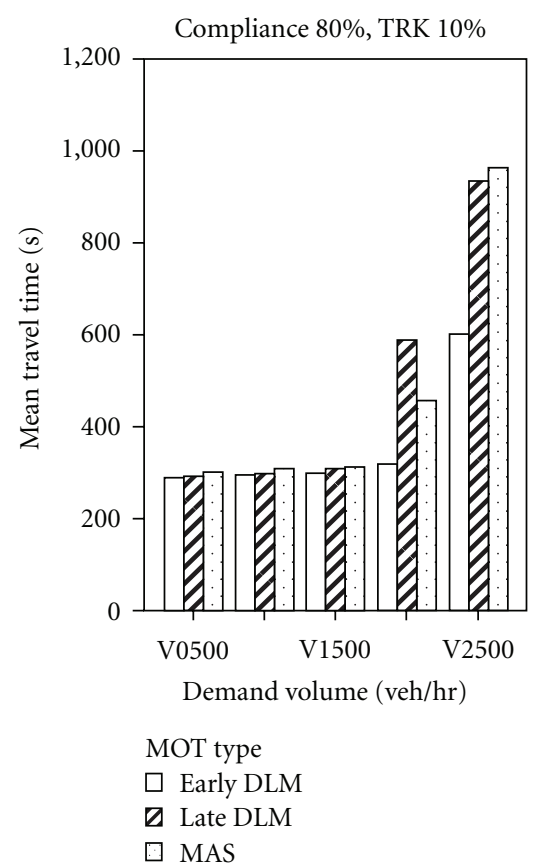

(d)

$$
\begin{aligned}
& \text { MOT type } \\
& \square \text { Early DLM } \\
& \square \text { Late DLM } \\
& \square \text { MAS }
\end{aligned}
$$

(b)

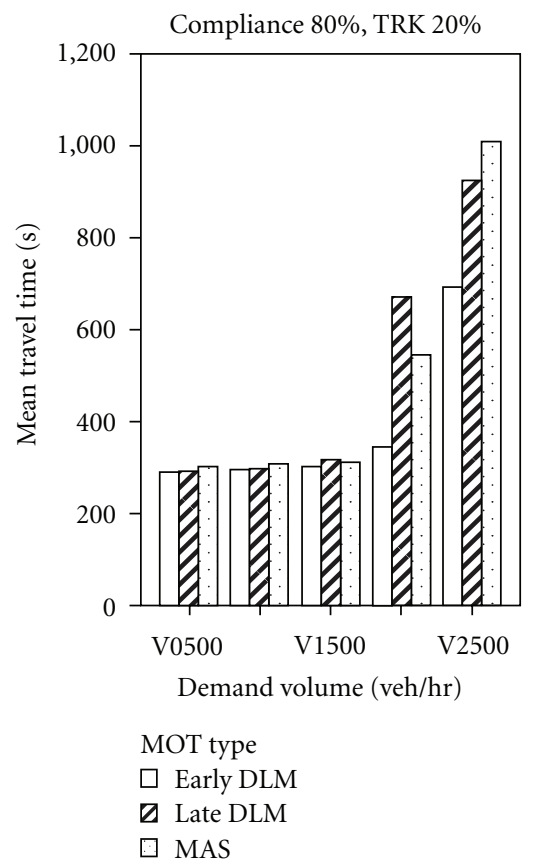

(e)

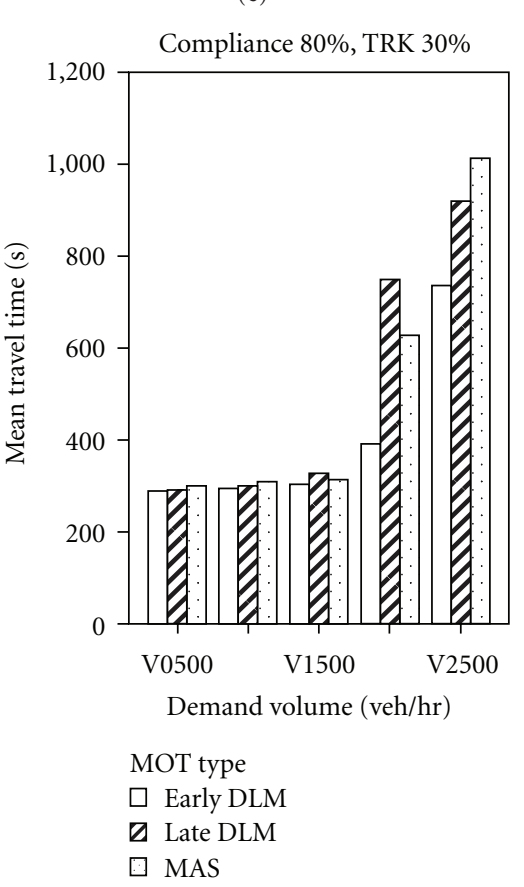

(f)

Figure 6: Travel time under different combinations (C60, C80).

trial and error procedure was followed in this calibration process. For each run in VISSIM, 10 iterations with different seed numbers were completed. Table 1 summarizes significant runs completed in VISSIM for the early SDLMS calibration. For instance, in run, 2 the headway time (CC1) was increased to 1.5 seconds, the following variation (CC2) was increased to $50 \mathrm{ft}$, and the safety reduction factor (SRF) was increased to 0.5 . The resulting simulated mean travel time (253.63 seconds) was significantly larger than the field measured travel time $(P$ value $=0.001$; error $\sim 10 \%)$. In this case VISSIM, was overestimating travel time. In run 4, $\mathrm{CC} 1$ and SRF were kept constant while CC2 was decreased to $35 \mathrm{ft}$. The resulting simulated mean travel time ( 244.03 seconds) was not statistically significantly different than the 
field measured travel time ( $P$ value $=0.157$; error $\sim 5.75 \%)$. Since the default parameter values provided lower errors, the calibration process was continued. In run $6, \mathrm{CC} 1$ was decreased to 1.25 second, CC2 maintained at $35 \mathrm{ft}$, and the SRF reduced to 0.35 . The resulting simulated mean travel time (241.60 seconds) was not statistically significantly different than the field measured travel time $(P$-value $=$ 0.27 ; error $\sim 4.69 \%)$. The reader may refer to Table 1 for all presented significant runs.

The validation of the VISSIM work zone models (early SDLMS, late SDLMS, and MAS) is also shown in Table 2. Work zone throughput was selected as the MOE for validation. A different field dataset is used for that purpose. The driver behavior parameters of the best runs from the calibration process (runs 7, 8, 9, 10,11, and 12) were used in the validation process and field observed throughputs and simulated throughputs were compared. The late SDLMS and the MAS were validated using the same driver behavior parameter set of the best runs determined in the calibration of the early SDLMS (see Table 2).

Looking at the overall calibration and validation process of the early SDLMS, late SDLMS, and MAS, the driving behavior parameters of run 12 were selected since they resulted in the most acceptable errors. The final headway time (CC1) value is 0.5 seconds, the following variation (CC2) value is $10 \mathrm{ft}$, and the safety reduction factor (SRF) is 0.40 .

\section{Simulation and Results}

As mentioned earlier, the objective of the simulation study is to determine the effectiveness of each MOT type (early SDLMS, late SDLMS, and MAS) under different driver's compliance rate, different truck percentage in the traffic composition, and different traffic demand volumes. For that purpose, different levels of each of these variables were considered. Four different levels of drivers' compliance rate, C20 (20\% of drivers comply to the merging instruction), C40 (40\% of drivers comply to the merging instruction), C60 (60\% of drivers comply to the merging instruction), and C80 ( $80 \%$ of drivers comply to the merging instruction) are created. Three different levels of truck percentage in the traffic composition are created, T10 (trucks constitute 10\% of the demand volume), T20 (trucks constitute $20 \%$ of the demand volume), and T30 (trucks constitute $30 \%$ of the demand volume). Five different traffic demand volume levels are created. V0500 means that the traffic demand volume is $500 \mathrm{veh} / \mathrm{hr}$. V1000 means that the traffic demand volume is $1000 \mathrm{veh} / \mathrm{hr}$. V1500 means that the traffic demand volume is $1500 \mathrm{veh} / \mathrm{hr}$. V2000 means that the traffic demand volume is $2000 \mathrm{veh} / \mathrm{hr}$. V2500 means that the traffic demand volume is $2500 \mathrm{veh} / \mathrm{hr}$. Having 4 compliance rate levels, 3 truck percentage levels, and 5 traffic demand volume levels resulted in 60 combinations for each of the early and late SDLMS. For the MAS, there is no compliance rate since there is no merging instructions, therefore the MAS has a total of 15 combinations. For each run (or combination) 10 iterations with different seed number were executed.
6.1. Work Zone Throughputs. The objective of this simulation study is to determine the MOT with the best performance under different combinations. Tables 3(a) and 3 (b) and Figures 3 and 4 provide a summary statistics of the work zone throughputs, under each combination. Ideally, we would like to know under each demand volume level, each compliance rate level, and truck percentage level, which MOT type results in the highest throughout. Therefore, for each combination an overall $F$-test was conducted with a null hypothesis that mean throughputs under all three MOT types are the same. If the null hypothesis is rejected, pairwise Tukey's comparisons are completed to determine the difference between each pair of throughput means. In Tables 3(a) and 3(b), under last three columns, the shaded areas mean that there was no need for pairwise comparison of means since the F-test null hypothesis was not rejected. In the same column, all mean differences superscripted with stars are significant at 0.05 significance level. From these tables, one can notice that under demand volumes V500, V1000, and V1500, there were no significant differences in the mean throughputs for all compliance rates and trucks percentage in the traffic.

However, for traffic demand volume levels V2000 and V2500 the early SDLMS results in the significantly highest mean throughputs compared to the late SDLMS under all combinations. Tables 3(a) and 3(b) show the early SDLMS compared to the MAS has significantly higher mean throughputs under all combinations except when the compliance rate is $20 \%$ and the truck percentage is $30 \%$. Comparing the MAS to the late SDLMS, the mean throughputs were the highest for the MAS under all combinations. Moreover, the differences were statistically significant except for three instances (combinations) C20T30 and V2500, C80T20, and V2500, C80 T30, and V2500.

For instance, Table 3(a) shows that for compliance rate of $20 \%$ and truck percentage $10 \%$, one can see that the early SDLMS has significantly higher throughput than the late SDLMS and MAS under demand volume levels V2000 and V2500. Looking at Tables 3(a) and 3(b) one can conclude that the early SDLMS resulted in the highest throughputs, followed by the MAS, then the late SDLMS under demand volumes which are close to capacity. The possible reason for this is that in a late merge the vehicles do not utilize available gaps between vehicles in the adjacent lanes and wait right till the end to get priority, as compared to MAS, in which lane changing occurs in the transition zone which results in lesser disruptions, and this is further true for early merge.

6.2. Travel Time through the Work Zone. Tables 4(a) and 4(b) and Figures 5 and 6 provide a summary statistics of the work zone travel times for each combination of compliance rate level, percentage trucks level in the traffic, and traffic demand volume level under each MOT type (early SDLMS, late SDLMS, MAS). Since preliminary analyses indicated inhomogeneous variances between travel times for each combination for the early SDLMS, late SDLMS, and MAS, a Levene's test is conducted for each combination with the null hypothesis that travel time variance under the early 
TABLE 5: Summary of operational MOEs.

\begin{tabular}{|c|c|c|c|c|c|c|c|}
\hline \multirow{3}{*}{ Compliance rate and percentage truck } & \multirow{3}{*}{ Volume } & \multicolumn{6}{|c|}{ Operations } \\
\hline & & \multicolumn{3}{|c|}{ Throughputs } & \multicolumn{3}{|c|}{ Travel time } \\
\hline & & MAS & Early DLM & Late DLM & MAS & Early DLM & Late DLM \\
\hline \multirow{5}{*}{ C20\% TRK 10\% } & V0500 & & & & & & \\
\hline & V1000 & & & & & & \\
\hline & V1500 & & & & & & \\
\hline & V2000 & 2 & 1 & 3 & 2 & 1 & 3 \\
\hline & V2500 & 2 & 1 & 3 & 3 & 1 & 2 \\
\hline \multirow{5}{*}{ C20\% TRK 20\% } & V0500 & & & & & & \\
\hline & V1000 & & & & & & \\
\hline & V1500 & & & & 1 & 1 & 2 \\
\hline & V2000 & 2 & 1 & 3 & 2 & 1 & 3 \\
\hline & V2500 & 2 & 1 & 3 & 2 & 1 & 2 \\
\hline \multirow{5}{*}{ C20\% TRK 30\% } & V0500 & & & & & & \\
\hline & V1000 & & & & & & \\
\hline & V1500 & & & & 1 & 1 & 2 \\
\hline & V2000 & 2 & 1 & 3 & 2 & 1 & 2 \\
\hline & V2500 & 2 & 1 & 3 & 2 & 1 & 2 \\
\hline \multirow{5}{*}{ C40\% TRK 10\% } & V0500 & & & & & & \\
\hline & V1000 & & & & & & \\
\hline & V1500 & & & & 2 & 1 & 3 \\
\hline & V2000 & 2 & 1 & 3 & 2 & 1 & 3 \\
\hline & V2500 & 2 & 1 & 3 & 2 & 1 & 2 \\
\hline \multirow{5}{*}{ C40\% TRK 20\% } & V0500 & & & & 3 & 2 & 1 \\
\hline & V1000 & & & & 3 & 1 & 2 \\
\hline & V1500 & & & & 2 & 1 & 3 \\
\hline & V2000 & 3 & 1 & 3 & 2 & 1 & 3 \\
\hline & V2500 & 2 & 1 & 3 & 2 & 1 & 2 \\
\hline \multirow{5}{*}{ C40\% TRK 30\% } & V0500 & & & & 2 & 1 & 1 \\
\hline & V1000 & & & & 3 & 1 & 2 \\
\hline & V1500 & & & & 2 & 1 & 3 \\
\hline & V2000 & 2 & 1 & 3 & 2 & 1 & 3 \\
\hline & V2500 & 2 & 1 & 3 & 3 & 1 & 2 \\
\hline \multirow{5}{*}{ C60\% TRK 10\% } & V0500 & & & & 3 & 2 & 1 \\
\hline & V1000 & & & & 3 & 2 & 1 \\
\hline & V1500 & & & & 2 & 1 & 3 \\
\hline & V2000 & 2 & 1 & 3 & 2 & 1 & 3 \\
\hline & V2500 & 2 & 1 & 3 & 2 & 1 & 2 \\
\hline \multirow{5}{*}{ C60\% TRK 20\% } & V0500 & & & & 3 & 1 & 2 \\
\hline & V1000 & & & & 3 & 1 & 2 \\
\hline & V1500 & & & & 2 & 1 & 3 \\
\hline & V2000 & 2 & 1 & 3 & 2 & 1 & 3 \\
\hline & V2500 & 2 & 1 & 3 & 2 & 1 & 2 \\
\hline \multirow{5}{*}{ C60\% TRK 30\% } & V0500 & & & & 3 & 1 & 2 \\
\hline & V1000 & & & & 3 & 1 & 2 \\
\hline & V1500 & & & & 2 & 1 & 3 \\
\hline & V2000 & 2 & 1 & 3 & 2 & 1 & 3 \\
\hline & V2500 & 2 & 1 & 3 & 2 & 1 & 2 \\
\hline
\end{tabular}


Table 5: Continued.

\begin{tabular}{|c|c|c|c|c|c|c|c|}
\hline \multirow{3}{*}{ Compliance rate and percentage truck } & \multirow{3}{*}{ Volume } & \multicolumn{6}{|c|}{ Operations } \\
\hline & & \multicolumn{3}{|c|}{ Throughputs } & \multicolumn{3}{|c|}{ Travel time } \\
\hline & & MAS & Early DLM & Late DLM & MAS & Early DLM & Late DLM \\
\hline \multirow{5}{*}{ C $80 \%$ TRK 10\% } & V0500 & & & & 3 & 1 & 2 \\
\hline & V1000 & & & & 3 & 1 & 2 \\
\hline & V1500 & & & & 3 & 1 & 2 \\
\hline & V2000 & 2 & 1 & 3 & 2 & 1 & 3 \\
\hline & V2500 & 2 & 1 & 3 & 2 & 1 & 2 \\
\hline \multirow{5}{*}{ C $80 \%$ TRK 20\% } & V0500 & & & & 3 & 1 & 2 \\
\hline & V1000 & & & & 3 & 2 & 1 \\
\hline & V1500 & & & & 2 & 1 & 2 \\
\hline & V2000 & 2 & 1 & 3 & 2 & 1 & 3 \\
\hline & V2500 & 2 & 1 & 3 & 3 & 1 & 2 \\
\hline \multirow{5}{*}{ C80\% TRK 30\% } & V0500 & & & & 3 & 1 & 2 \\
\hline & V1000 & & & & 3 & 1 & 2 \\
\hline & V1500 & & & & 2 & 1 & 3 \\
\hline & V2000 & 2 & 1 & 3 & 2 & 1 & 3 \\
\hline & V2500 & 2 & 1 & 3 & 3 & 1 & 2 \\
\hline
\end{tabular}

SDLMS, late SDLMS, and MAS is homogenous (see Tables 4(a) and 4(b). If the null hypothesis is rejected, Friedman's nonparametric test is conducted for each combination with the null hypothesis that travel times means (early SDLMS, late SDLMS, and MAS) are equal. If the null hypothesis is rejected meaning that at least one travel time mean is different than the others, then unequal variance pairwise $t$ tests are conducted. In Tables 4(a) and 4(b), under last three columns, the shaded areas mean that there was no need for pairwise comparison of means since the $F$-test or Friedman's test null hypothesis was not rejected.

In Table 4(a), for compliance rate of $20 \%$ and truck percentage $10 \%$, one can see that the early SDLMS has significantly lower travel than the late SDLMS and MAS under demand volume levels V2000 and V2500. However, comparing the late SDLMS to the MAS, MAS has a significantly lower travel time mean under demand volume level V2000 and a significantly higher travel time under demand volume V2500. For a compliance rate of $20 \%$ and truck percentage of $20 \%$ and $30 \%$, the early SDLMS resulted in statistically significant lower travel times compared to the late SDLMS under demand volume levels V1500, V2000, and V2500 and statistically significant lower travel times compared to MAS under demand volume levels of V2000 and V2500. The MAS has a significantly lower travel compared to the late SDLMS at demand volume levels V1500 and V2000 for 20\% and V1500 for 30\% trucks. For other levels of compliance rate, the reader may refer to Tables 4(a) and $4(\mathrm{~b})$.

\section{Conclusions and Recommendations}

The operational effectiveness of the three MOT types, namely,ss the MAS, the early SDLMS, and the late SDLMS was examined. Table 5 summarizes the operational effectiveness of the three MOT types. In Table 5, the first three columns under operations summarize the throughputs for each combination of compliance rate, truck percentage in the traffic composition, and demand volume level. Only statistically significant results are presented in this table. For each combination the results were numbered 1,2 , and 3 . One meaning that it is the best to use, 2 meaning the second best to use, and 3 meaning the third best to use. The best MOT types to use, numbered 1 , are highlighted in this table. For instance, one may want to know which MOT type is best for a work zone at a demand volume level of $1500 \mathrm{veh} / \mathrm{hr}$, truck percentage of $20 \%$, and compliance rate of $60 \%$. In this case " 1 " is the best MOT types denoting early SDLMS. Therefore, the recommendations are presented in Table 5. The cells left blank in Table 5 reflect no significant difference between the combinations.

It is noticed from Table 5 that for most compliance rates and truck percentage levels in the traffic composition, the early SDLMS outperforms the MAS and the late SDLMS in terms of throughputs and travel times. Future research may focus on analyzing the safety aspect of the three MOT types using speed variance, deceleration rates, and so forth.

\section{References}

[1] A. Tarko and S. Venugopal, "Safety and capacity evaluation of the Indiana lane merge system," Tech. Rep. FHWA/IN/JTRP/2000/19, Purdue University, West Lafayette, Ind, USA, 2001.

[2] A. G. Beacher, M. D. Fontaine, and N. J. Garber, "Evaluation of the Late Merge Work Zone Traffic Control Strategy," Report VTRC-05-R6, Virginia Transportation Council, 2004.

[3] A. Tarko, S. Kanipakapatman, and J. Wasson, "Modeling and optimization of the Indiana lane merge control system on approaches to freeway work zones," Final Report 
FHWA/IN/JTRP-97/12, Purdue University, West Lafayette, Ind, USA, 1998.

[4] P. T. McCoy, G. Pesti, and P. S. Byrd, "Alternative information to alleviate work zone related delays," SPR-PL-1(35) P513, University of Nebraska-Lincoln, 1999.

[5] Wayne State University, Department of Civil and Environmental Engineering, "Dynamic Lane Merge Traffic Control System: A Strategy for Alleviating Aggressive Driving Behavior at Work Zones in Michigan," 2001.

[6] P. T. McCoy and G. Pesti, "Dynamic late merge control concept for work zones on rural interstate highway," in Proceedings of the 80th Annual Meeting of the Transportation Research Board, Washington, DC, USA, 2001.

[7] E. Meyer, "Midwest Smart Work Zone Deployment Initiative," Construction Area Late Merge (CALM) System, 2004, http://ntl.bts.gov/lib/9000/9500/9529/Meyer1.pdf.

[8] URS, "Dynamic Late Merge System Evaluation: Initial Deployment on US-10," Minnesota Department of Transportation, 2003.

[9] URS, "Evaluation of 2004 Dynamic Late Merge System," Minnesota Department of Transportation, 2004.

[10] L. F. Grillo, T. K. Datta, and C. Hartner, "Evaluation of the dynamic late lane merge system at freeway construction zones," in Proceedings of the 87th Annual Meeting of the Transportation Research Board, Washington, DC, USA, 2008.

[11] "Florida Department of Transportation. Plans Preparation Manual (Chapter 10. Work Zone Traffic Control)," 2008, http://www.dot.state.fl.us/rddesign/PPMManual/2012/ Volume2/2012Volume2.pdf.

[12] R. Harb, E. Radwan, S. Ramasamy, M. Abdel-Aty, and S. Putcha, "Two simplified ITS-based Lane Management strategies for Short term work zones," in Proceedings of the 88th Annual Meeting of the Transportation Research Board, Washington, DC, USA, 2009.

[13] VISSIM User Manual, "Version 4.30. P. T. V. AG," Karlsruhe, Germany, 2007.

[14] Traffic Analysis Toolbox, "Volume III: Guidelines for Applying Traffic Microsimulation Modeling Software," Federal Highway Administration United States Department of Transportation, Research, Development, and Technology Turner-Fairbank Highway Research Center. McLean, Va, USA, 2004.

[15] I. Chatterjee, E. Praveen, M. Sandeep, and S. Carlos, "Replication of work zone capacity values in a simulation model," in Proceedings of the 88th Annual Meeting of the Transportation Research Board, Washington, DC, USA, 2009. 

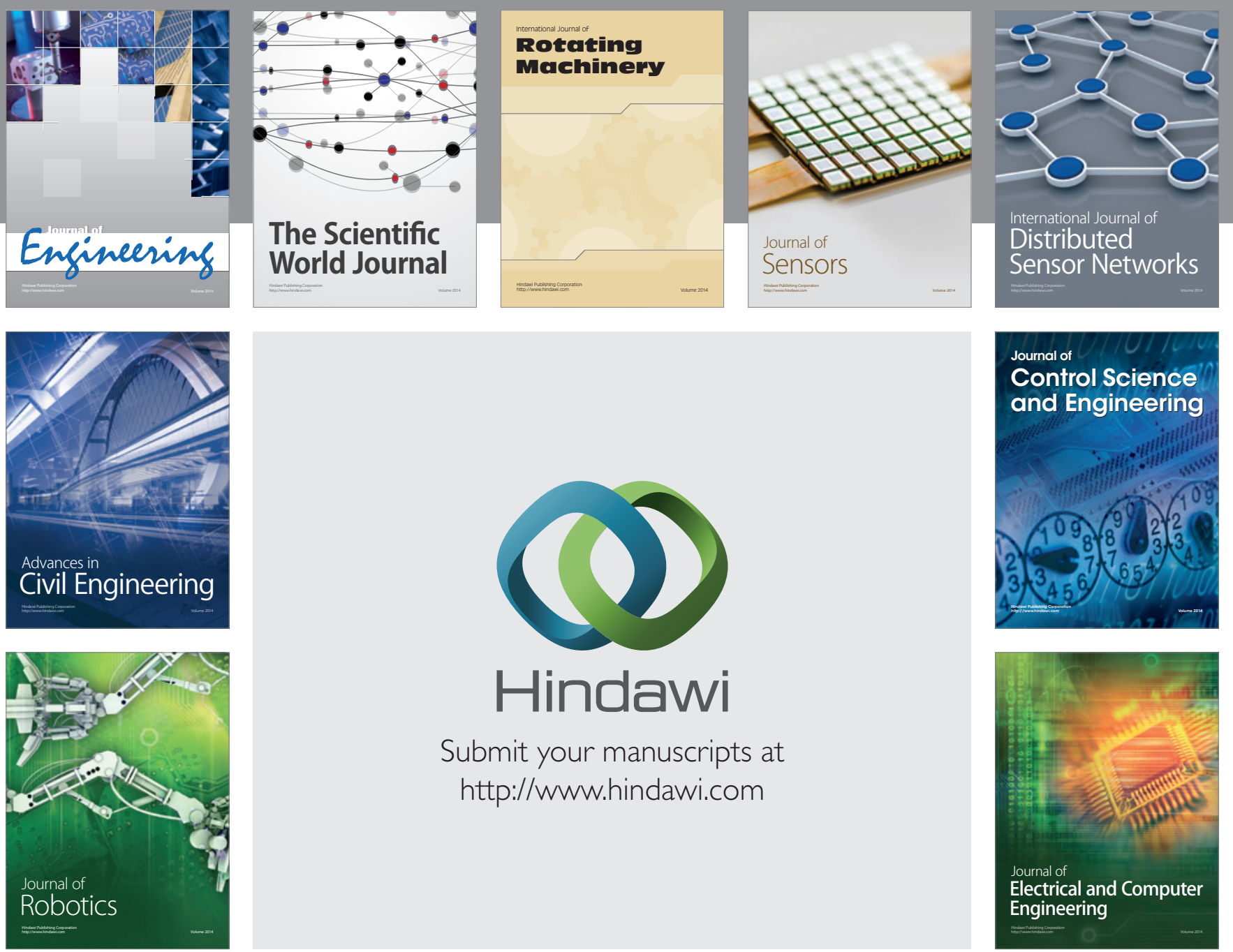

Submit your manuscripts at

http://www.hindawi.com
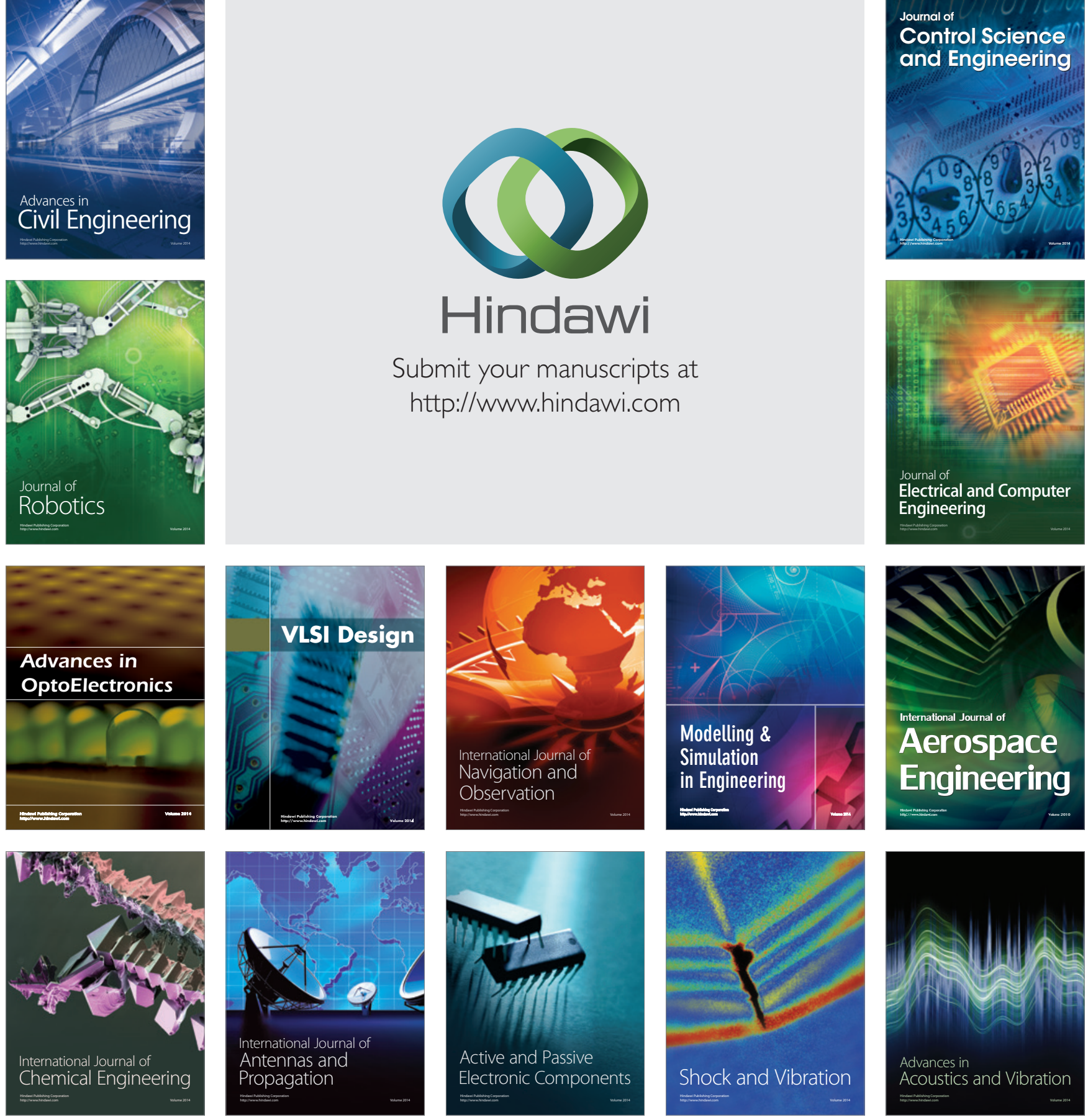